\title{
VISITA DOMICILIÁRIA SOB O OLHAR DE USUÁRIOS DO PROGRAMA SAÚDE DA FAMÍLIA ${ }^{1}$ THE HOUSE CALL AS SEEN BY FAMILY HEALTH PROGRAM USERS LA VISITA DOMICILIARIA VISTA POR USUARIOS DEL PROGRAMA SALUD DE LA FAMILIA
}

\author{
Edir Nei Teixeira Mandú², Maria Aparecida Munhoz Gaíva3, Maria da Anunciação Silva3, Ana Maria \\ Nunes da Silva ${ }^{4}$
}

${ }^{1}$ Estudo realizado pela linha de pesquisa Trabalho, Cuidados e Subjetividades em Saúde e Enfermagem (Grupo Argos). Faculdade de Enfermagem da Universidade Federal do Mato Grosso (UFMT).

${ }^{2}$ Doutora em Enfermagem. Professora associado da Faculdade de Enfermagem da UFMT. Mato Grosso, Brasil.

${ }^{3}$ Doutora em Enfermagem. Professora adjunto da Faculdade de Enfermagem da UFMT. Mato Grosso, Brasil.

${ }^{4}$ Graduanda do Curso de Enfermagem da UFMT. Bolsista do Programa Institucional de Bolsas de Iniciação Científica do Conselho Nacional de Desenvolvimento Científico e Tecnológico. Mato Grosso, Brasil.

PAL A V R A S - C H A V E: Programa Saúde da Família. Visita domiciliar. Atenção primária à saúde.

KEYWORDS: Family Health Program. Home visit. Primary health care.

PALABRAS CLAVE: Programa Salud de la Família. Visita domiciliaria. Atención primaria de salud.
RESUMO: Através de uma pesquisa qualitativa são analisados significados atribuídos por famílias à visita domiciliária realizada pelo Programa Saúde da Família, com a intenção de reconhecer dificuldades e potenciais acumulados em torno dessa prática. Entre outubro e dezembro de 2005, foram feitas 30 entrevistas abertas com mulheres e 10 com homens, todos entre 18 e 79 anos e residentes a mais de seis meses em uma região de saúde de Cuiabá - MT. Na categorização dos dados utilizou-se a análise de conteúdo. A visita é concebida como um meio importante de aproximação entre o Programa de Saúde da Família e as famílias, favorecendo o acesso aos serviços, a construção de novas relações entre os usuários e a equipe e a formação de vínculo entre estes. Ela é valorizada como alternativa ao acesso a cuidados clínicos e à vigilância à saúde, reiterando-se a prática realizada. Ao mesmo tempo espera-se que ela responda de forma mais abrangente às necessidades vividas.

ABSTRACT: Through a qualitative study, meanings attributed to the house call by Brazilian families who benefited from the Family Health Program are analyzed, with the objective of recognizing the difficulties and potential accumulated from this practice. From October to December of 2005, thirty women and ten men participated in open interviews, all between 18 and 79 years old as well as more than six-month residents in a health region of Cuiabá, MT, Brazil. Content analysis was used for data interpretation. The house call is conceived as an important method of approaching the Family Health Program and families, favoring greater access to its services, the construction of new relationships between users and the health care team, and the creation of a link between them. It is valued as an alternative to access to clinical care and to health monitoring, reiterating the practice carried out. At the same time, one hopes that it responds to the necessities it faces in the most broadened form possible.

RESUMEN: Por medio de un estudio cualitativo son analizados los significados atribuidos por las familias a la visita domiciliaria realizada por el Programa Salud de la Familia, con el objetivo de reconocer las dificultades y los potenciales relacionados con esta práctica. Entre octubre y diciembre de 2005 fueron hechas treinta entrevistas abiertas con las mujeres y diez con los hombres, todos ellos entre 18 y 79 años, residentes por más de seis meses en una regional de salud de Cuiabá - MT. La categorización de los datos se hizo por medio del análisis del contenido. Se considera la visita como una importante forma de aproximación entre el Programa Salud de la Família y las familias, favoreciendo el acceso a los servicios, la construcción de nuevas relaciones entre los usuarios y el equipo de salud, y, la formación de un vínculo entre ellos. La visita domiciliaria se presenta como una alternativa importante para el acceso a los cuidados clínicos y de vigilancia a la salud, reiterando la práctica de la visita tal como recibida. $\mathrm{Al}$ mismo tiempo, se espera que ella promueva respuestas más amplias a las necesidades vividas.
Edir Nei Teixeira Mandú

Endereço: R. Marcos Pereira da Luz, 111, Ap. 402

78.048-590 - Miguel Sutil, Cuiabá, MT, Brasil.

Email: enmandu@terra.com.br
Artigo original: Pesquisa

Recebido em: 11 de maio de 2007 Aprovação final: 07 de janeiro de 2008 


\section{INTRODUÇÃO}

O Brasil iniciou a implantação do Programa Saúde da Família (PSF) no início da década de 1990, em função do alcance da universalidade da atenção básica à saúde e de sua melhoria. A partir da Norma Operacional Básica de 1996, este passou a ser considerado estratégia reestruturante de todo o sistema de saúde, expandindo-se no país. O estado do Mato Grosso iniciou a implantação dessa política em 1996, apresentando uma cobertura de Equipes de Saúde da Família (ESF) de 52.6\% em dezembro de 2006, acima do percentual nacional de 46.2\%. Em Cuiabá - MT, a implantação do PSF ocorreu em 1998, encontrando-se uma cobertura local de 19,9\% naquela mesma data. ${ }^{1}$

O PSF tem como desafios não só ampliar o acesso às ações de saúde mas, dar forma concreta a uma interpretação ampla de saúde e às idéias de integralidade da atenção, promoção da saúde, enfoque familiar, desenvolvimento de co-responsabilidades, humanização da assistência, e formação de vínculo entre profissionais e população territorializada. ${ }^{2}$ Para dar corpo a esse novo modelo, entre as várias ações projetadas e em execução encontra-se a prática sistemática das visitas domiciliárias*, realizada pelas ESFs. Na política nacional direcionada ao PSF, cabe a toda a equipe realizar o cuidado em saúde da população adscrita, tanto no âmbito dos serviços, como do domicílio e demais espaços comunitários. ${ }^{4}$

Embora as visitas não sejam uma estratégia nova no âmbito da saúde pública brasileira, ${ }^{5}$ na atualidade, elas têm finalidades mais amplas e se tornaram bastante complexas. Na segunda década do século XX, a visita voltava-se para o cuidado do doente e aos fatores relacionados com a sua doença, sem preocupação com a família enquanto grupo social. ${ }^{6} \mathrm{Na}$ proposta do PSF, a visita deve se articular aos desafios que se colocam para este, tendo as famílias, em seu contexto sociocultural de vida, como unidade central de atenção, ${ }^{2}$ abarcando suas diversas necessidades, tendo em vista não só a prevenção da saúde e a recuperação e reabilitação de doenças mas, também, a promoção da saúde.

Considerando, assim, a importância da visita domiciliária no fortalecimento das mudanças da atenção básica bem como a sua complexidade, através de pesquisa realizada em uma dada região de saúde de Cuiabá em que o PSF encontra-se implantado, analisou-se essa prática a partir do olhar e da experiência de membros de famílias enfocando dois eixos: a sua visão acerca da saúde-doença e de necessidades a serem atendidas pelo PSF e pelas visitas; e suas percepções e expectativas em torno destas. Neste artigo, discute-se este segundo eixo.

A construção da qualidade almejada para o PSF, responsabilidade de todas as áreas profissionais da saúde, requer a consideração aos múltiplos sentidos atribuídos às suas práticas concretas pelos diferentes atores nelas envolvidos e, em especial, os usuários. A despeito disto, as visitas domiciliárias, do ângulo posto aqui em evidência, não têm sido abordadas pelos estudos científicos.

Propõe-se, então, uma aproximação da prática da visita através dos significados que lhe são atribuídos por membros de famílias que a recebem, tendo por objetivo analisar suas concepções e reconhecer dificuldades, avanços e potenciais acumulados em torno desta estratégia. Do ponto de vista prático, objetiva-se a produção de subsídios à qualificação do trabalho em saúde da família e ao desenvolvimento de profissionais em atenção primária.

\section{METODOLOGIA}

O tema abordado constitui parte de um estudo qualitativo, descritivo-analítico, realizado nas áreas de abrangência de oito Unidades de Saúde da Família (USFs), de uma região de saúde de Cuiabá - MT, com pelo menos dois anos de funcionamento no momento da coleta dos dados (outubro-dezembro de 2005), uma vez que nestas a visita já se encontrava consolidada.

Conforme informações levantadas diretamente nessas unidades, através de seus profissionais, a visita sistemática é sobretudo atividade dos Agentes Comunitários de Saúde (ACSs), sendo direcionada a todas as famílias das áreas territorializadas, para ações de cadastramento, orientação e vigilância à saúde. A visita também é realizada por médicos e enfermeiros, especialmente para controles clínicos julgados por estes como necessários, com certa variabilidade entre as equipes.

O estudo orientou-se por uma perspectiva dialética, com base em debates nacionais em torno do tema presentes no âmbito da saúde coletiva e da enfermagem. Assumiu-se como pressuposto básico que há relação entre os significados atribuídos à visita domiciliária e o modo predominante de produção desta e os processos de vida, carências e sofrimentos enfrentados de modo próprio pelas famílias, caracterizando-se tal significação

* Termo usado como adjetivo, significando o "que é feito no domicilio". ${ }^{3}$ 
como uma construção social permeada por contradições. Esse entendimento apóia-se em uma interpretação gramsciana, ${ }^{7}$ que considera que os diferentes grupos sociais concebem o mundo de modo compartilhado, em meio às condições reais de vida, apresentando idéias comprometidas com o pensamento dominante e com a própria condição de classe, incluindo ambigüidades e elaborações próprias frente a questões do cotidiano.

Constituíram-se sujeitos do estudo membros de famílias residentes nas áreas de abrangência das unidades selecionadas, escolhidos a partir da indicação das equipes e de contatos aleatórios feitos de forma direta pelos pesquisadores nas USFs ou no próprio domicílio, considerando a diversificação das áreas. Definiu-se como critérios de inclusão na pesquisa ser residente das áreas selecionadas há mais de 6 meses, receber visita domiciliária sistematicamente e aceitar participar da pesquisa.

Os dados aqui discutidos foram obtidos através de entrevistas abertas orientadas por questões relacionadas ao perfil sócio-demográfico dos entrevistados e por dois temas nucleares à pesquisa: experiências de cada informante em torno da visita domiciliária; e o seu ponto de vista sobre a mesma. Essas entrevistas foram aplicadas a 40 informantes: 30 mulheres $(75 \%)$ e 10 homens $(25 \%)$, entre 18 e 79 anos, residentes a mais de um ano na região selecionada, com exceção de dois moradores que nela residiam entre 7 e 9 meses. Na definição desse número de participantes foi levado em conta o critério de saturação de dados. ${ }^{8}$

O projeto foi aprovado pelo Comitê de Ética em Pesquisa do Hospital Universitário Júlio Muller, de Cuiabá - MT, sob o protocolo $\mathrm{N}^{\mathrm{o}}$ 181/04, atendendo a todos os requisitos exigidos pela Resolução 196/96 do Conselho Nacional de Saúde, incluindo a assinatura do Termo de Consentimento Livre e Esclarecido. Para manter-se o anonimato dos participantes, estes são aqui apresentados mediante o código " $U$ ", significando usuário ou usuária, seguido por um número dado a cada entrevista.

No tratamento dos dados utilizou-se a análise de conteúdo temática, com a intenção de evidenciar qualitativamente os significados emergentes do material levantado. ${ }^{9}$ Este processo contemplou os dados empíricos em suas particularidades, articulados aos objetivos da pesquisa, aos pressupostos adotados e à bibliografia consultada. Os resultados do eixo recortado neste artigo são apresentados e debatidos através da categoria "Concepções em torno da prática da visita do- miciliária", construída a partir da caracterização, pelos entrevistados, das intenções e do conteúdo da visita, da apresentação de suas expectativas e de aspectos de sua realização realçados como positivos, problemas, e/ou dificuldades.

\section{CONCEPÇÕES EM TORNO DA PRÁTICA DA VISITA DOMICILIÁRIA}

\section{A visita como meio de facilitação do acesso aos serviços e ações de saúde}

Entre os informantes que têm uma visão positiva acerca da realização da visita domiciliária, encontra-se de forma recorrente a idéia de que esta é uma prática importante.

Pra mim a visita é importante. Dá uma ajuda de saúde mesmo, por ver minha situação. Às vezes, como estou doente e, por acaso, não posso ir lá, dá uma felicidade deles vim aqui e ver minha situação, eles cuida de mim e passa remédio (U 32).

A menção a sua importância atrela-se à facilitação do acesso e a características que se coadunam com problemas vividos e/ou valorizados e com a aceitação de tecnologias assistenciais disponíveis. Por exemplo, como revela a fala acima, essa importância advém da vivência de uma situação interpretada como doença e do reconhecimento da visita como um meio que facilita o acesso, no próprio domicílio, a cuidados individualizados e a uma dada tecnologia assistencial valorizada (prescrição de remédio).

De outro modo, tal importância articula-se ao fato de a visita favorecer o reconhecimento da vivência de um dado problema de saúde e provocar a procura do serviço local. Veja-se a seguir: eu acho bom [as visitas] porque às vezes a gente é despercebida. Tem uma coisa e fala: - Isso eu não vou não [na USF]! Não tem importância! Mas às vezes tem! (U 16).

A visita é vista como uma estratégia que viabiliza intermediação entre o domicílio e a Unidade de Saúde da Família (USF) e vice-versa, ao favorecer o acesso ao serviço local através da comunicação de reuniões a se realizarem na USF, de informações sobre as suas rotinas e do agendamento prévio de atendimentos.

Sempre que tem reunião, ela [ACS] passa avisando; ela avisa que dia que é (U 31).

A gente pergunta os horários de atendimento lá [USF]. Ela [ACS] sempre indica (U 4).

Aqui, ela [ACS] só vem e pergunta se precisa de remédio, ai ela marca lá para ir consultar [...] (U 14). 
Entende-se que a visita evita ou deve evitar que aquele que tem uma dada necessidade precise se deslocar até a USF para ser atendido, em situações em que a pessoa se vê e/ou está impossibilitada de se deslocar pela doença, por falta de tempo, por uma deficiência, em uma situação de desconforto, ou em casos considerados de urgência.

Têm muitos que tem necessidade e não podem ir no posto. Tá doente, de cama. Então, quando a agente tá passando, ela chama o médico que vem em casa e atende. [...] Porque tem gente aqui que é deficiente. Essa pessoa tem condição de ir no posto? Se vier alguém buscar ela tem condição (U 7).

[...] Ás vezes eu tô ocupado no comércio e não tenho tempo para ir lá. E se eles passassem por aqui seria melhor. Porque eu que sou hipertenso. [...] Ai, se eles passassem aqui, já tirava a pressão da gente. [...] Aqui [em Cuiabá] é muito quente (U 18).

Se tem o posto eles deveriam vir pra dar uma olhada, falar: - Não, ela tá mesmo passando mal. Vou lá ver o que eles tão precisando mais (U 10).

Evidenciando a importância da visita para a equidade da atenção, entrevistados criticam o fato de algumas famílias não a receberem ou manifestam o desejo de que sua família seja visitada mais freqüentemente, afirmando-se que alguns grupos e/ou situações merecem prioridade.

[...] Acho que eles deveriam freqüentar mais as casas. [...] A gente sabe que tem muita casa pra ir, mas acho que diabético e hipertenso deveria ter um olhar diferente, e idoso também. Mas é tudo igual! (U 14).

Como em boa parte do mundo, no Brasil vêm ocorrendo mudanças no perfil demográfico e epidemiológico de sua população, tais como a maior longevidade e o aumento das doenças crônicodegenerativas. A expansão da atenção domiciliária (da qual a visita é uma modalidade), inclusive, articula-se entre outras razões a essas mudanças. Os idosos e portadores de problemas como diabetes e hipertensão, entre outros problemas, tornam-se cada vez mais dependentes de cuidados domiciliares, na perspectiva da vigilância, manutenção e restauração de sua saúde. ${ }^{10}$ De modo que, a vivência dessas situações na família de entrevistados se expressa na forma de demanda canalizada para as visitas, sendo estas reconhecidas como parte do arsenal social e tecnológico de que se dispõe no enfrentamento daquelas situações.

A partir dessa caracterização inicial da visita pelos entrevistados e de aspectos que valorizam, pode-se destacar: a sua importância para a ampliação da equidade e acesso à atenção; e sua valorização por sua correspondência com expectativas existentes em torno do acesso a cuidados assistenciais.

Esses dois aspectos são coerentes com os princípios da universalidade, equidade e integralidade, assim como com a proposição da humanização, no que diz respeito à superação de dificuldades em torno do acesso e à aceitação da população das práticas dos serviços de saúde. De igual modo, eles também são condizentes com a proposta do $\mathrm{PSF}^{4}{ }^{4}$ que tem em vista a ampliação do acesso aos serviços e ações de saúde e a atenção abrangente à diversidade e singularidade das necessidades e demandas das famílias.

Contudo, é preciso considerar que as características destacadas e/ou valorizadas e a necessidade de sua potencialização remetem, entre outros aspectos, à problematização da possibilidade de a visita vir a promover acomodação, causando dependência e desestímulo a um envolvimento mais ativo das famílias na superação de condições adversas enfrentadas. Essa é uma preocupação do Ministério da Saúde (MS). Segundo este órgão, ${ }^{11}$ as visitas no PSF devem ser realizadas rotineiramente otimizando-se a utilização de recursos humanos e evitando a dependência da população dos profissionais (especialmente do médico).

O enfrentamento dessa questão não é simples. Ele se situa no interior de um debate a ser encaminhado no âmbito dos municípios e USF, em torno das finalidades e conteúdos das visitas, das condições existentes nos serviços locais à sua concretização, acerca das necessidades e responsabilidades dos usuários/famílias e das ESFs na produção da saúde, bem como sobre a participação dos primeiros na busca de seu próprio desenvolvimento e no enfrentamento de condições desfavoráveis de vida e saúde.

Nesse debate, é preciso ponderar que a visita é vista como positiva também por se colocar como alternativa frente à acomodação de usuários / famílias no enfrentamento de seus problemas de saúde, substituindo a falta de um movimento visto como necessário.

É ótimo [a visita]. Bom, porque se a gente tiver algum problema já fala. Daí eles já levam lá [...]. Já fica sabendo da necessidade do pessoal. [...] Porque tem gente que fica doente e parado dentro de casa, e não sai nem pra procurar médico nem nada (U 24).

De outro modo, ela é valorizada como meio estimulador da busca do direito à assistência à saúde, ainda que este movimento seja provocado via mecanismos de controle aos quais não se elabora uma crítica. 
Os que mais precisam são os pobres e eles têm vergonha. Não sabem seus direitos e não vão à procura. [...] Nós sabemos nossos direitos. É porque eles passam, levam, falam, chamam, então as pessoas acabam indo! Porque se você não tiver alguém pra incentivar... [...] Tá sempre passando, falando. Aí a pessoa acaba ficando sem-graça e vai (U 21).

Enfrentar essa contradição é um elemento importante no debate em torno da visita domiciliária, articulado à crítica sobre a forma como esta se concretiza e ao modo como através dela se lida com direitos, com a educação e a produção, ou não, de autonomia.

Cabe observar que a sua realização deve considerar necessidades priorizadas, através de processos de planejamento compartilhado, e intencionar a participação autônoma dos usuários/ famílias na melhoria de suas condições de vida, coerentemente com a perspectiva de promoção da saúde. Nesse sentido, as visitas não podem se constituir em ação centralizada nas necessidades da equipe, e sim nas necessidades daqueles.

\section{A visita como meio ao acesso a ações assisten- ciais e de vigilância à saúde tradicionais}

Na caracterização da visita como meio ao acesso a cuidados em saúde, visualiza-se evidente destaque, dado pelos entrevistados, a componentes tecnológicos da prática clínica tradicional (a remédios, procedimentos clínicos e atendimentos médi$\cos )$, por estes se encontrarem, ou não disponíveis.

Tem que vir ver como é que tá. Se tá precisando [...] de um remédio, se precisa de um socorro assim, no ato de uma doença. Isso que eu acho (U 8).

[...] A minha mulher sempre tá fazendo uma cirurgia que tem curativo e aí não tem como ir lá, porque não tem carro pra levar, e eles não vêm buscar. [...] Sempre quando precisa eles vêm, mas teve uma época que eu tive que fazer curativo (U 10).

Encontra-se a expectativa de que as visitas sejam realizadas com maior freqüência ou sistematicamente, especialmente pelo médico(a), valorizando-se inclusive especialidades: o ponto negativo na visita é a falta de especialistas junto. Um mais estudado, eu acho que falta uma pessoa dessa maneira. [...] Um pediatra. Pra mim, eu acho que se ela vinha com a enfermeira a pessoa sente mais segurança (U 21).

Na política nacional delineada para o PSF e na prática concreta as visitas têm se constituído especialmente em atribuição dos ACSs, cabendo aos demais profissionais a sua realização em situações específicas definidas. ${ }^{4}$ Coerentemente, em
Cuiabá, a visita é realizada sobretudo pelos ACSs sendo estes os trabalhadores que estabelecem mais fortemente o vínculo entre os usuários/famílias e a USF/equipe, característica essa valorizada por entrevistados. Porém, o destaque dado ao médico(a) e eventualmente ao enfermeiro(a) atrela-se à compreensão de que estes estão "mais preparados" para as situações que destacam como passíveis de visita, coerentemente com as demandas de atenção clínica que possuem e com a importância social atribuída a esses profissionais (especialmente ao médico).

Os procedimentos clínicos demandados indicam a valorização do acesso a direitos sociais históricos, que constituem parte das respostas a que têm acesso através do modelo assistencial tradicional - centrado em procedimentos e na resolução da doença. Mas é preciso considerar, também, que esses componentes transformam-se em necessidades e demandas em meio aos sofrimentos vividos. Nesse sentido, eles representam demandas legítimas frente às experiências e direitos dos sujeitos, pois se vinculam a carências enfrentadas e a conquistas sociais em torno de alternativas existentes para resolvê-las.

Certamente não é possível negligenciar direitos, sobretudo considerando condições de saúde-doença e dificuldades enfrentadas de acesso à atenção no âmbito do SUS e PSF. Porém, é preciso reconhecer que essas idéias refletem e reforçam o perfil presente de atuação das USFs locais, perfil esse que se busca transformar através do SUS e PSF. Assim, o PSF e a prática da visita precisam enfrentar esta questão, com a efetiva participação crítica dos envolvidos - famílias e trabalhadores - o que certamente requer a produção de novas experiências que sirvam como novas referências assistenciais sobretudo para as famílias.

A integralidade da atenção coloca-se em perspectiva quando, entre outros aspectos, integram-se ações curativas, preventivas e de promoção da saúde. No PSF, projeta-se o encaminhamento de ações com essas diferentes naturezas, de forma integrada, de modo a responder a demandas espontâneas, a ações programadas, estratégicas e de vigilância à saúde. ${ }^{4}$ No processo de territorialização, são tidos como essenciais: a identificação de problemas e riscos de grupos, famílias e indivíduos; a atualização de informações sobre condições de vida e saúde-doença; a realização de busca ativa e notificações de doenças e agravos; e o encaminhamento de ações preventivas e promocionais de saúde. A visita é tida como um dos meios de viabilização dessas ações, devendo 
participar da atenção a demandas, de ações programadas, estratégicas e de vigilância.

Alguns desses componentes projetados para as visitas e concretizados, em alguma medida, são realçados na descrição e apreciação de entrevistados desta pesquisa. Ao relatarem as atividades realizadas por trabalhadores em seus domicílios, estes a vinculam à identificação de problemas de saúde na família e, também, à oferta de informações e ações educativas, valorizando estes aspectos: a visita dela é importante também, por que ela [ACS] dá orientação. [...] Então a orientação dela vale a pena. Muita gente tem vergonha de ir ao posto [...]. Aí dá aquela informação e daquela informação dá uma reação (U 30).

Na política direcionada à atenção básica, a produção e mobilização de informações, assim como a realização de ações educativas e de vigilância à saúde, reafirmadas entre entrevistados, são apresentadas como objetivos da visita domiciliária. ${ }^{4}$

Nesse sentido, identifica-se que assim como os depoimentos circulam em torno da aplicação de cuidados clínicos, estes também se atrelam mais diretamente às ações tradicionais de vigilância à saúde realizadas, com destaque, ao controleestímulo à adoção de práticas de autocuidado e prevenção (valorizando-se o controle do uso de medicamentos, da prática de imunização, realização de exames preventivos etc.): igual ela [ACS] fala: - Olha, tem que fazer a prevenção. - Já tá na hora. - Olha tem que fazer tal consulta. Tá pegando no meu pé para fazer a consulta pós-parto (U 2).

Quando ela [ACS] chega aqui, briga comigo, sobre o meu tratamento, porque eu sou hipertensa. Ela chega e eu estou tossindo e coloco sal na boca: - Tá colocando sal na boca? - Que é isso? - Vai lá e pede um xarope. Ela é muito importante (U 18).

São evidenciadas e valorizadas atividades de vigilância relacionadas a ações estratégicas encaminhadas localmente: de acompanhamento do desenvolvimento infantil e da gestação; de prevenção do câncer genital; de controle da imunização, hipertensão e diabetes; dentre outras.

Neste núcleo também se encontra uma importante questão relacionada à visita que deve ser objeto de reflexão crítica especialmente, em relação à forma tradicional com que se trabalha a vigilância de problemas priorizados.

Na política do PSF destaca-se um dado perfil de vigilância à saúde - de controle de riscos e agravos, através da produção de informações familiares/populacionais, de ações educativas e do controle de práticas de autocuidado em saúde. ${ }^{4}$
Entre as atribuições das equipes propõe-se a visita para monitorar a situação de saúde das pessoas no espaço do domicílio segundo critérios epidemiológicos e de risco. A visita com essa finalidade implica no desenvolvimento de ações de prevenção e monitoramento dirigidas a grupos específicos, às doenças prevalentes e a situações de risco. ${ }^{12}$

A visita em Cuiabá articula-se em torno dessa perspectiva de vigilância e seu perfil concreto conforma, em alguma medida, as demandas apresentadas e as ações valorizadas pelos entrevistados.

Cabe considerar que, por um lado, as visitas são instrumentos de trabalho preciosos no cuidado estratégico da saúde das famílias, devendo ser utilizadas nas mais diferentes formas de acompanhamento de seus membros, em suas situações peculiares de saúde-doença e nos diferentes momentos de seu ciclo vital. ${ }^{5}$ A visita é essencial ao processo de vigilância à saúde, tendo por finalidade acompanhar a situação de saúde de cada membro da família, esperando-se a produção de resultados positivos através da antecipação de diagnósticos personalizados, do atendimento e de maior orientação ao indivíduo e sua família. ${ }^{13}$

Por outro lado, é preciso ponderar que o desenvolvimento de ações no domicílio aproxima o trabalho profissional da dinâmica de vida das famílias, colocando em cena seus modos de lidar com a vida e os problemas de saúde, questões de subsistência, aspectos religiosos e culturais, afetividades e outras subjetividades, que implicam em desafios para os profissionais. ${ }^{14}$ Nesse sentido, as famílias que se encontram em situação de maior vulnerabilidade devem ser apoiadas intensivamente.

A aproximação dessas duas perspectivas, assim, é essencial, de forma que as especificidades dos cuidados direcionados a situações peculiares de saúde-doença na família não anulem a sua abrangência e vice-versa. A idéia de monitoramento da saúde-doença, proposta pela política de atenção básica, não deve se consolidar como uma prática de controle sobre a vida e os comportamentos em saúde das pessoas, bloqueando-se a ação direcionada a necessidades mais abrangentes e à produção de autonomia, seja dos seus membros ou da família como um todo, pois estas características remetem à esperada ampliação do acesso e equidade.

\section{A visita como resposta às necessidades vividas}

Os limites de uma perspectiva centrada na vigilância à saúde dirigida a grupos específicos, a 
doenças prevalentes e situações de risco, ainda que não apontados explicitamente pelos entrevistados, são confrontados e contraditoriamente expressos através do reconhecimento de que a visita deve responder mais ampla e efetivamente a necessidades vividas. Nesse sentido, encontra-se a afirmação de que a visita atende apenas parcialmente às necessidades enfrentadas: as necessidades que a gente tá precisando [a visita] não ajuda totalmente; mas já adianta um pouquinho (U 14).

Porque quem trabalha nesse ramo [das visitas domiciliárias] tem que trabalhar para atender as necessidades dos outros. E isso não está acontecendo (U 12).

Nessa direção, são feitas críticas à falta de resolutividade da visita: pra perguntar se tá bem qualquer um pergunta! Se perguntar se tô bem, eu digo: - Tô bem! Falar: - A senhora tá bem? Isso não refresca nada! (U 5).

O PSF propõe inovações na organização e dinâmica da assistência mediante tecnologias que permitam a aproximação das ações e dos profissionais das pessoas, famílias e comunidades, tendo por intenção a identificação e prestação de atenção segundo suas reais necessidades. ${ }^{4} \mathrm{~A}$ vinculação a necessidades concretas da população caracteriza o enfoque familiar e comunitário e disto depende a produção de impacto na direção das mudanças pretendidas - de produção de qualidade de vida, saúde e humanização da atenção. ${ }^{15}$

Por um lado, identificar necessidades no domicílio, uma prática comumente dos ACSs, cria expectativas em torno de respostas por parte dos serviços, e provocam críticas especialmente se estas não são levadas a cabo. Por outro, os limites das práticas do PSF e da visita experimentados pelas pessoas, em meio a condições e necessidades vividas e a interpretações dadas, remetem à falta de consonância entre estes.

A crítica aos limites da visita articula-se, sobretudo, à falta de respostas a demandas por assistência clínica, em meio ao reconhecimento social dado a esta na resolução de questões de saúde-doença, como mencionado. Nesse conjunto, necessidades de vida não são apontadas como parte das responsabilidades das USFs e da visita, em meio a um processo social de naturalização das mesmas: bem a única coisa que me falta aqui e que a gente precisava era dinheiro. Isso a gente não pode pedir. A gente não pode pedir para elas [integrantes da equipe de saúde] as nossas necessidades. Porque trabalhar eu não posso. [...] (U 22).

A organização e oferta da atenção no PSF centradas em ações clínico-educativas estratégicas, como ocorrem em Cuiabá, restringem a identificação de outras possibilidades como pertinentes ao âmbito da atenção à saúde e, também, a expressão destas segundo experiências e significados próprios dos usuários. Na prática assistencial predominante a abordagem da saúde-doença segundo a sua natureza social não é valorizada. Assim, esta característica tende a ser ocultada na significação atribuída por entrevistados a suas necessidades e aos cuidados de saúde vistos como imprescindíveis para resolvê-las, demandando-se das visitas, sobretudo, ações coerentes com as práticas tradicionais dos serviços.

Contudo, também são manifestas contradições em torno desse perfil de prática, ainda que não remetidas especificamente às visitas, pois em meio às difíceis condições de vida enfrentadas também se revela, a partir de uma visão mais abrangente de saúde, a necessidade de algum grau de comprometimento do PSF com dificuldades sociais.

Tanta família mais carente que a nossa aí. Deveria ajudar! Como eu falei: - tem o centro comunitário; tá vago. O que custava o prefeito, o presidente [de bairro], a turma da saúde da família falar: - Oh! Vamos colocar um negócio de crochê! [...] Eu acho que deveria ter uma pintura, um crochê, uma coisinha a mais! Pra desenvolver mais a saúde [...] (U 10).

Essa perspectiva encontrada é especialmente coerente com o projeto de reorganização da atenção básica proposto no Brasil, que prevê a ampliação do objeto de ação para além da dimensão biológica e individual da saúde-doença. Nas proposições ministeriais para o PSF, a despeito de um perfil assistencial centrado no controle dos riscos e agravos, afirma-se a necessária consideração à inter-relação entre a prática clínica e a promoção da saúde. ${ }^{4}$ Assim, a visita deve ter por finalidade transformar o perfil de saúde-doença da população e não apenas atender queixas e situações pontuais através de intervenções específicas. ${ }^{3}$ Nesse sentido, essa prática deve se sintonizar com a perspectiva de promoção, favorecendo inovações importantes no processo de enfrentamento da saúde-doença com a participação das famílias.

Em sentido estrito, a integralidade da atenção à saúde, um dos princípios do PSF, envolve novas posturas profissionais, inter-relações entre serviços sociais e de saúde, e novos elementos organizativos e de produção das ações de saúde. Vincula-se também, diretamente, ao reconhecimento e enfrentamento das especificidades dos sofrimentos e dos contextos e condições que os geram. ${ }^{16}$

Desse modo, a visita precisa avançar face à intencionalidade de antecipação e redução do 
sofrimento dos sujeitos, por consideração à sua relação com os contextos, abarcando alternativas frente a questões de ordem sociocultural, realçando a perspectiva promocional em saúde. Esta, em sentido amplo, abarca a mobilização de distintos recursos, estratégias e atores (Estado, serviços de saúde, outros setores, organismos de apoio social etc.) na geração de qualidade de vida e saúde; abrange, também, a efetiva participação dos sujeitos/coletivos nas definições em torno de questões próprias de vida e saúde e na adoção de estratégias coletivas de enfrentamento das necessidades vividas. Em sentido mais restrito, ela diz respeito à complementaridade entre conhecimentos, práticas, linguagens técnicas e populares e ao desenvolvimento de habilidades à manutenção de vida saudável. Além disso, abarca práticas integradas de atenção às demandas, de vigilância e atuação nas causas básicas da saúde-doença. ${ }^{17}$

A visita, portanto, deve ter por intuito subsidiar o planejamento de ações produzindo informações sociais e epidemiológicas que revelem características homogêneas e distintas dos grupos territorializados, visando à promoção da saúde de famílias. ${ }^{18} \mathrm{O}$ atendimento no domicílio também deve ser realizado com o objetivo de trabalhar a proteção da saúde através de uma abordagem inter-relacional e educativa em prol do desenvolvimento de potencialidades individuais e coletivas no enfrentamento de condições adversas. Deve apoiar-se no uso de tecnologias que favoreçam o enfrentamento das causas geradoras de necessidades de saúde, apoiando-se em uma prática interdisciplinar, intersetorial e articulada à rede social existente. A visita não deve se restringir a medidas assistenciais encaminhadas pelas equipes do PSF e/ou pelos serviços de saúde, apoiando-se apenas em tecnologias tradicionais, requerendo articulações para fora do setor saúde e a produção de um novo potencial tecnológico. Nesse sentido, as visitas e a prática de educação em saúde devem ser instrumentos articulados e encaminhados com um caráter emancipatório, tendo em vista não só a prevenção mas também a promoção da saúde.

Na perspectiva da integralidade e promoção da saúde, o PSF projeta a família como unidade central de suas práticas, vista a partir do ambiente onde vive, das suas inter-relações, estrutura e dinâmica. ${ }^{4} \mathrm{O}$ domicílio, assim, é local privilegiado para o reconhecimento e desenvolvimento de ações direcionadas à saúde da família, considerando que neste âmbito ocorrem relações sociais que se constituem em riscos que concorrem para o adoecimento ou em potenciais que favorecem a sobrevivência e o enfrentamento de dificuldades. ${ }^{3}$ A visita, assim, possibilita a aproximação das dificuldades e potenciais socioculturais e relacionais das famílias, para enfrentamento de suas vulnerabilidades e produção de cidadania.

Apesar dessa direcionalidade, nas entrevistas realizadas localiza-se um vazio em relação à vinculação das visitas a características e potenciais da família como um todo. O que é coerente com o fato de que, em Cuiabá, como em outros municípios brasileiros, esta não é o sujeito das visitas e sim os seus membros. No Brasil, a abordagem familiar não tem se constituído efetivamente em alvo de ações no PSF ou em espaços comunitários, requerendo tanto o reconhecimento dessa possibilidade como o desenvolvimento e uso de tecnologias para tal.

\section{A visita como meio de acolhimento e vínculo}

O conjunto das entrevistas revela que entre os aspectos valorizados na visita encontram-se a atenção, a conversa e o comprometimento profissional. Com esse perfil, visualiza-se que a visita gera a produção de auto-estima, de esperança e bem-estar (inclusive para o próprio profissional): a visita dá uma auto-estima que é preciso; quando eles vêm fazer uma visita, parece que eles vêm trazer uma nova esperança, uma nova vida. [...] O pessoal que vem visitar se sente melhor e aquele que recebe também se sente melhor (U 35).

As relações afetivas estreitas, estabelecidas com o profissional através da visita, como as que ocorrem com os ACSs, são especialmente valorizadas: a gente gosta muito dela [ACS]. [...] Eu dou muito valor a ela porque ela chega aqui e quer saber como que a gente tá, como que tá a saúde. [...] Ela é uma pessoa muito boa aqui para nós. [...] Ela é muito gentil, muito direita (U 18).

A canalização, ou não, de demandas através das visitas, inclusive, apóia-se no reconhecimento de condições de acolhimento do vivido e do apoio buscado. O respeito à vida privada e o comportamento ético são apresentados como essenciais à abertura do domicílio às ações profissionais: a minha irmã não fez acompanhamento [pré-natal], porque ficou grávida e essa [ACS] foi contar para o bairro inteiro. Aí a minha mãe achou ruim [...] (U 32).

A visita, por sua proximidade, é vista como facilitadora da abordagem de questões tidas como da ordem do privado: talvez a pessoa tenha vergonha 
de chegar lá... É doença da rua, doença venérea, tem muita doença que a pessoa tem vergonha de ir no posto. Então, junto de casa eu acho que a pessoa se sente mais à vontade pra relatar (U 30).

O PSF visa a mudanças na relação entre os profissionais e a população, valorizando o respeito às pessoas/famílias, o estabelecimento de vínculos e a criação de laços de compromisso e co-responsabilização entre aqueles. ${ }^{4}$

Nesse último sentido, aponta-se como positivo o comprometimento dos ACSs com a família através de sua participação ativa na resolução de problemas enfrentados por esta: se precisava de um remédio e tava caro para comprar, porque às vezes eles passam remédio para comprar, aí ele [ACS] falava: - me dá a receita que eu vou conseguir lá na prefeitura. Aí ele já ia na prefeitura e conseguia o remédio (U 28).

A humanização da atenção encontra-se na base das propostas de transformação dos cuidados em saúde, estabelecendo como características de qualidade da assistência, entre outros aspectos, o "bom" relacionamento, a ampliação do processo comunicacional, o reconhecimento de direitos e da cultura dos usuários, opondo-se às violências praticadas nos serviços. As tecnologias leves (acolhimento, vínculo e autonomização) devem sustentar as principais reestruturações do cuidado em saúde, a serem inscritas em todo trabalho do setor. ${ }^{19}$

Essas características, por sua presença ou ausência nas visitas, são apreciadas pelos entrevistados, que assim reafirmam a necessidade de construir práticas humanizadas. A perspectiva valorizada é a do direito a ser ouvido, respeitado e considerado em suas necessidades, realçandose aspectos relacionais importantes à mudança das práticas em saúde a serem potencializados através da visita.

\section{A visita como prática secundária e objeto de confrontação}

A visita, ainda que valorizada, ocupa um papel secundário na resolução de necessidades de saúde enfrentadas, evidenciando-se a vinculação desta, mais expressivamente, à dinâmica interna da USF. Essa percepção atrela-se ao fato de que é no âmbito dos serviços que as famílias localizam e experimentam respostas mais resolutivas às necessidades enfrentadas/valorizadas, através de tecnologias aceitas e tidas como da ordem dos serviços de saúde.

Além disso, e dos aspectos positivos sinalizados em relação à visita, esta também provoca resistência entre a população, sendo objeto de recusa e confrontação.

A visita freqüente e compulsória, nem sempre é bem-vinda e há quem a veja como importante e necessária, mas não para a própria família. As visitas, significando intromissão do setor saúde na vida das pessoas, interferem em sua liberdade e essa característica é em alguma medida recusada por entrevistados.

Outra forma de resistência manifesta-se na afirmação de que a visita desconsidera conhecimentos e posições próprias frente ao cuidado em saúde (num confronto ao processo de medicalização da vida): ela [ACS] briga comigo, às vezes, que eu to tomando uma dose [cerveja]. [...] Pede para eu não fazer aquilo. Eu falei pra ela: - A vida da gente não podemos viver só em torno de remédio. Você tem que tomar remédio, mas [...] a pessoa também pode dizer: Hoje eu vou tomar uma cerveja, vou comer uma carne gorda e não vou tomar insulina (U 23).

Apesar de a ação educativa na visita ser referida como positiva, também se evidencia e confronta a sua realização através de uma prática profissional impositiva, que desvaloriza conhecimentos e decisões em torno do cuidado à saúde.

O caráter compulsório da visita, as suas práticas de controle, a forma impositiva como através dela se lida com o conhecimento e a educação das pessoas não são coerentes com a humanização da atenção e a participação autônoma dos sujeitos nas decisões que lhes dizem respeito. De modo que, outro desafio para a visita é se concretizar a partir da permissão, de processos de diálogo e do respeito aos conhecimentos, valores e práticas das famílias.

\section{CONSIDERAÇÕES FINAIS}

Ao analisar as concepções dos participantes desta pesquisa em torno da visita domiciliária, foi possível identificar a reafirmação de um conjunto de necessidades e direitos no campo da atenção básica à saúde: ao acesso amplo aos serviços e suas tecnologias; à equidade na oferta de ações; ao acesso a componentes da clínica e vigilância à saúde tradicionais; ao acesso a respostas mais amplas e efetivas a necessidades vividas: a ser bem tratado e respeitado em suas recusas e conhecimentos.

Essas concepções articulam-se em torno de suas experiências e interpretações que merecem, como um ponto de vista peculiar, consideração na construção da qualidade desejada para o PSF. Nesse sentido, os posicionamentos encontrados remetem à reflexão em torno dos limites e poten- 
ciais acumulados em torno da visita domiciliária, considerando que as idéias apresentadas, além de reafirmarem uma dada perspectiva de direitos também refletem e reforçam o perfil tradicional de atuação das USFs que se busca transformar.

Destacam-se, assim, por um lado, seus limites dados pela concentração em torno de procedimentos clínico-educativos e de ações estratégicas de vigilância, direcionadas aos indivíduos, que situam como secundários a produção de autonomia, a promoção da saúde, o cuidado amplo a necessidades e ao núcleo familiar. Por outro lado, se evidenciam seus potenciais, sobretudo por suas características de ampliação do acesso aos cuidados, de ampliação de vínculo e humanização da atenção à saúde.

Desse modo, evidencia-se a necessidade de refletir coletivamente em torno dessa estratégia, de enfrentar suas dificuldades e de reafirmar e desenvolver seus potenciais acumulados, por referência a cada contexto específico, às suas peculiaridades e às interpretações dos sujeitos envolvidos. Nesse sentido, considerando e interpretando os significados sociais em torno do que cada grupo envolvido concebe como qualidade desejável, segundo suas experiências, valores, interesses e motivações.

Coloca-se, ainda, a relevância de debater em que medida a visita domiciliária tem contribuído para a reorientação dos processos de trabalho das USFs e de revê-la em suas finalidades, seus objetos, conteúdos, modos e meios de execução e em sua articulação com outros espaços. A adoção de uma política clara para essa prática e de mecanismos para o seu monitoramento e avaliação alia-se à importância de melhor articulá-la ao trabalho local, dos demais níveis do sistema, e de outros setores e instituições e práticas sociais.

\section{REFERÊNCIAS}

1 Ministério da Saúde (BR), Departamento de Atenção Básica. Histórico de cobertura da saúde da família [acesso em 2006 Dez 30]. Disponível em: http:// dtr2004.saude.gov.br/dab/

2 Vilasbôas ALO. Marco referencial e conceitual da atenção básica e saúde da família no Brasil [Notas preliminares]. Brasília (BR): MS; 2003.

3 Egry EY, Fonseca RMGS. A família, a visita domiciliária e a enfermagem: revisitando o processo de trabalho da enfermagem em saúde coletiva. Rev. Esc. Enferm. USP. 2000 Set; 34 (3): 233-9.

4 Ministério da Saúde (BR), Secretaria de Atenção à Saúde, Departamento de Atenção Básica. Política Nacional de Atenção Básica. Brasília (DF): A Secretaria; 2006.
5 Reinaldo MAS, Rocha RM. Visita domiciliar de Enfermagem em saúde mental: idéias para hoje e amanhã. Rev. Eletrônica de Enferm. 2002 Jul-Dez; 4 (2): 36-41.

6 Fallate BSC, Barreira IA. Significados da visita domiciliar realizada pelas enfermeiras de saúde pública nas décadas de 20 e 30. Esc. Anna Nery: rev. enferm.1998 Dez; 2 (3): 73-85.

7 Gramsci A. Concepção dialética da história. 7a ed. Rio de Janeiro (RJ): Civilização Brasileira; 1991.

8 André MEDA. Texto, contexto e significados: algumas questões na análise de dados qualitativos. Cad. Pesqui.1983 Mai; 45: 66-71.

9 Gomes R. Análise de dados em pesquisa qualitativa. In: Minayo MCS, organizadora. Pesquisa social: teoria, método e criatividade. Petrópolis (RJ): Vozes; 1994. p.67-80.

10 Rechem TCMSB, Trad LAB. Assistência domiciliar em saúde: subsídios para um projeto de atenção básica brasileira. Ciênc. Saúde Colet. 2005 Jul-Set; 10 (supl.): 231-42.

11 Ministério da Saúde (BR), Secretaria de Atenção à Saúde, Departamento de Atenção Básica. Saúde da Família: uma estratégia para reorientação do modelo assistencial. Brasília (DF): A Secretaria; 1997.

12 Chiesa AM, Fracolli LA. O trabalho dos agentes comunitários de saúde nas grandes cidades: análise do seu potencial na perspectiva da promoção da saúde. Rev. Bras. Saúde Fam. 2003 Jan-2004 Abr; 5 (7): 42-9.

13 Tulio EC, Stefanelli MC, Centa ML. Vivenciando a visita domiciliar apesar de tudo. Fam. Saúde Desenv. 2000 Jul-Dez; 2 (2): 71-9.

14 Martins JJ, Albuquerque GL, Nascimento ERP, Barra DCC, Souza WGA Pacheco WNS. Necessidades de educação em saúde dos cuidadores de pessoas idosas no domicílio. Texto Contexto Enferm. 2007 Abr-Jun; 16 (2): 254-62.

15 Rosa W, Labate RCA. Contribuição da saúde mental para o PSF. Rev. Bras. Enferm. 2003 Maio-Jun; 56 (3): 230-5.

16 Schraiber LB. Desafios atuais da integralidade em saúde. Jorn. Rede Feminista Saúde. 1999 Maio 17; p.1-4.

17 Buss PM. Promoção da saúde e qualidade de vida. Ciênc. Saúde Colet. 2000 Jan-Jul; 5 (1): 163-77.

18 Takahashi RF, Oliveira MAC. A visita domiciliária no contexto da saúde da família. In: Instituto para o Desenvolvimento da Saúde, Universidade de São Paulo, Ministério da Saúde (BR). Manual de Enfermagem. Brasília (DF): MS; 2001. p.43-6.

19 Merhy EE. Em busca da qualidade dos serviços de saúde: os serviços de porta aberta para a saúde e o modelo técnico-assistencial em defesa da vida. In: Cecílio LCO, organizador. Inventando a mudança na saúde. 2a ed. São Paulo (SP): Hucitec; 1997. p.117-60. 